\title{
PROJETO CONVIVÊNCIA INTERGERACIONAL NA UNIVERSIDADE DE CRUZ ALTA: RESULTADOS FINAIS DA ESCALA FRABONI DE IDADISMO
}

Rômulo José Barboza dos Santos; Universidade de Cruz Alta (UNICRUZ); romullobarboza@hotmail.com

Solange Beatriz Billig Garces; UNICRUZ; sbgarces@hotmail.com

Diego Paes Ehmke; UNICRUZ; diegopaes.ehmke@gmail.com

Pâmela Fanfa Ribeiro Gonçalves; UNICRUZ; pfgoncalves2001@hotmail.com

\section{RESUMO}

Introdução: A palavra intergeracional dialoga com as relações existentes entre indivíduos que pertencem a gerações distintas, em todos os contextos da vida social, não apenas em um contexto específico, como o familiar. Quando possibilitada a convivência intergeracional, a velhice recebe um novo significado, tendo em vista que o envelhecer em sociedade vem acompanhado por sérios problemas, como discriminação, exclusão e preconceito. Objetivo: investigar entre os colaboradores da UNICRUZ, atitudes e preconceitos em relação ao envelhecimento. Métodos: abordagem qualitativa através da aplicação da Escala Fraboni de Idadismo a 146 colaboradores, possibilitando avaliar aspectos cognitivos e afetivos do preconceito, a partir de três níveis: Antilocução, Evitamento e Discriminação. Os dados foram dicotomizados para Discordo, Concordo e Estou em Dúvida. Resultados: buscamos avaliar o Evitamento, quando 55\% dos participantes discordaram que a maioria dos idosos deveria ser impedida de renovar suas carteiras de motorista. Acerca da Discriminação, esta foi avaliada quando questionados se os complexos esportivos deveriam ter sempre locais separados para que os idosos joguem entre si, em seu nível, onde 49\% dos participantes discordaram e, ainda, se a maioria dos idosos fica mais feliz quando está com pessoas de sua idade, em que 54\% assinalaram discordar. Já a Antilocução, foi avaliada quando $64 \%$ dos participantes discordaram que a maioria dos idosos está presa ao passado. Conclusão: de forma geral, entre os colaboradores da UNICRUZ, não há índices significativos de preconceito contra a pessoa idosa, tendo em vista suas respostas frente às diversas situações onde avaliamos os três níveis de preconceito.

Palavras-chave: Envelhecimento; Intergeracionalidade; Preconceito 